\title{
Integrating Gender Dynamics into Innovation Ecosystems
}

\author{
Elizabeth Pollitzer ${ }^{1, *}$, Martina Schraudner ${ }^{2}$ \\ ${ }^{1}$ Portia Ltd., UK \\ ${ }^{2}$ Fraunhofer Centre for Responsible Research and Innovation, Germany
}

Copyright (C) 2015 by authors, all rights reserved. Authors agree that this article remains permanently open access under the terms of the Creative Commons Attribution License 4.0 International License

\begin{abstract}
Innovation ecosystems can be constructed around any subject matter. We choose here the topic of gender, which we examine as a component of innovation success. Most analyses of innovation systems tend to assume gender-neutral position with regard to identity and roles of participating actors and their activities. However, real-life innovations can often result in different quality of outcomes for women and men; the innovation potential of highly trained women remains unrealised; and the recent socioeconomic empowerment of women as driver of market needs continues to be ignored. Drawing on latest research evidence from studies of gender issues in science, we show how innovation systems can benefit from adopting more gender sensitive approaches, which recognise the role gender plays in shaping knowledge and market activities. We propose four scenarios for constructing gender sensitive innovation ecosystems based on different gender dynamics that combine scientific understanding of sex and gender differences with improved engagement of women in innovation process, enabled through participatory methods and open and inclusive innovation practices.
\end{abstract}

Keywords Gender, Careers, Innovation Ecosystem, Women, Policy

\section{Introduction}

Innovation is often presented as a collective enterprise, involving industry, universities and governments as main actors, united through shared interest in commercialisation of applications arising out of research [1,2,3]. Although innovation systems that rely on collaboration between universities and industry are often described as 'open', they are strongly selective in who participates in knowledge development and exchange, what entrepreneurial activities are permitted, what markets are to be created, and how resources will be mobilised.

Because women are underrepresented in technology and engineering fields and sectors they are also in a minority in related innovation areas [4], which may partly explain why analyses of innovation systems tend to be conducted from a gender-neutral perspective. The purpose of this paper is to question the validity of the gender-neutral assumption by raising awareness of the role gender plays in shaping science knowledge and influencing markets, and by showing how effectiveness of innovation process and its outcomes can be improved by considering possible gender effects.

Hekkert 2011 [5] warns that many innovation systems are characterised by some 'flaws', which hamper the process of knowledge development and diffusion for the purpose of establishing opportunities to create new technologies and markets. The specific 'flaw' we wish to focus on concerns the unwanted consequences of adopting gender-neutrality in these contexts. The primary among them are: 1) differences in the efficacy of innovation outcomes for women and men; 2) underutilization of available female creative talent; 3 ) missed market opportunities; and 4) negative attitudes to innovation in society, as well as resistance to technological advancement. This can be exemplified by the history of innovation in speech recognition. The speech recognition algorithms were developed in acoustic labs full of men and so were tested on men. But male voices have different frequency to women's voices, and consequently, when the speech recognition software products were first introduced to the market they worked well for men but not so well for women, and much of the then market opportunity was lost because users' needs were assumed to be 'gender neutral' [6].

This example epitomises the illusion of gender neutrality in science knowledge, which in reality hides widespread gender bias that favours the use of male as the norm in research. It is an important motivation for examining gender issues in innovation, because if innovation is about utilising knowledge for socioeconomic benefits, and there are gender issues that are known to influence research results then it is very likely that they will also impact on quality of the innovation outcomes based on that research.

Drawing on results from multiple studies of gender issues in science, we hypothesise that making innovation sensitive and responsive to the effects of gender can: 1) enhance effectiveness of innovation process by enlarging and diversifying the pool of viable innovation ideas and solutions; 
2) improve innovation capacity through better deployment of available female human capital resources; 3) create new market opportunities for science knowledge; and 4) help engage more women in identifying their (and their family) innovation needs, as well as enabling them to use knowledge transfer and commercialisation activities as a source of potential employment.

Focused on innovation opportunities arising from scientific understanding of when, why and how sex and gender differences can influence outcomes for women and men, an open and inclusive innovation process, which utilises participatory methods in an effective way [7], can help facilitate the fuller engagement of women in innovation systems. They can bring into the innovation process wide range of experiences as socioeconomic agents and as highly trained individuals, located inside and outside formal innovation structures.

Our aim in this paper is to show how the current understanding of gender issues in science, which is supported by extensive evidence, can be used to improve innovation success. Based on this evidence, the important consequences to consider include: 1) widespread gender bias in science knowledge production, application and communication; 2) unequal conditions in development of scientific human capital of women and men; 3) prevalent gender bias in organisational practices and processes; and 4) systemic failure of institutions to comply with gender equality policies and regulations [8].

\section{Research Design}

We have combined three approaches to identify connections between known gender issues in science and conditions needed to support innovation success, including: 1) exploratory research to assess current perceptions of the roles gender can play in innovation; 2) analysis of open and inclusive innovation practices and their scope to promote gender sensitive knowledge exchange activities; and 3) analysis of the characteristics of career pathways in science and engineering-related areas that relevant to effective development of innovation human capital.

The important factor driving this investigation is the recent change in the perceptions and attitudes towards gender issues in science among policy makers and scientists, which is exemplified by the action taken by the European Commission to include gender as a criterion of success in the Framework Programme for Research and Innovation for 2014-2020, called Horizon 2020. The aim is to recognise and reward advancement of gender equality in research participation and the integration of gender as dimension in research content. Whereas, past Framework Programmes focused on promoting gender equality as a way of addressing the issue of women's underrepresentation in science, technology, engineering and mathematics fields (STEM), the new approach responds to the persuasive evidence showing widespread gender bias in science knowledge and science practice, and its effects on quality of research outcomes for women and men.

In short, science today has more evidence for men than for women because historically researchers tended primarily to use male subjects in experimental studies [9]; often also failing to disaggregate results by sex, even when both sexes were used [10]; and omitting to report the subjects' sex [11]. This means that research outcomes can be poorer for women than for men, and, therefore, this suggest that innovation outcomes may be affected in the same way [12].

The second important factor driving this investigation concerns the consequences of neglecting the innovation potential of highly trained women, located inside and outside of science establishments, as well as the consequences of overlooking women's growing socioeconomic empowerment, achieved through higher education and growing participation in the labour force. As researchers, taxpayers, opinion makers, and consumers (making purchasing decisions for themselves and for their families) women should play much more significant role in innovation than they have done so far.

We have considered in this investigation how the low presence of women in innovation relates to the women's underrepresentation in key science and technology fields. The latter is often summarised by the 'leaky pipeline' phenomenon, which shows that women are lost from science in much greater proportions than men, and at each career advancement step. Thus, for instance, even though in Europe more women than men obtain university degrees, at the highest level of a science career there are 80 per cent of men and 20 per cent of women [13].

With regard to the mechanisms enabling more women to be engaged in innovation, we have identified, analysed and learned from two examples of open and inclusive approaches to innovation, in particular, which can demonstrate concrete benefits of involving individuals and groups located outside formal innovation systems. The first concerns the Discover Markets method developed by Martina Schraudner, which has been successfully deployed at Fraunhofer [14]. The aim of this approach is to use participatory methods to open up the innovation process to individuals from non-engineering areas, and to special groups in society (e.g. the disabled), with the aim of involving them in market idea creation activities (e.g. for rehabilitation devices). The second example concerns the use of web-based 'crowd sourcing' techniques to open up the innovation process to large and dynamic population of potential problem solvers by broadcasting innovation problems through the web. This is exemplified by the website www.innocentive.com.

Finally, we investigated the career pathways of women and men working in areas key to innovation to identify features influencing their career and employment choices, and successes, which are relevant to participation in innovation activities. For this, we used two separate sources of data: a survey of 400 alumni from a technology university, and a database of $1100 \mathrm{CVs}$ of excellent women scientists and engineers. 


\section{Results}

\subsection{Constructing a Gendered Innovation Ecosystem}

The results of our analyses show that gender issues can have important consequences for innovation outcomes, and that this can be mitigated through greater awareness of what these issues and consequences mean in practice, and what are the benefits of addressing them. We propose the concept of gender sensitive innovation ecosystem. In theory, an innovation ecosystem can be constructed around any subject matter [15]. Figure 1 shows the different roles gender can play in influencing inputs into and outcomes of innovation activities at the knowledge side, at the market side, and within the 'valley of death'.

Traditionally, the 'valley of death' has been presented as a barrier to successful commercialisation of research knowledge, which has to be surmounted by securing additional investment (post research and post prototype) in the form of venture capital, bank loans, or special government grants. In a gender-sensitive innovation ecosystem, the knowledge side and the market side are brought closer together by using gender as the shared, enabling element through which innovation ideas and market needs can be identified, examined, and their value as contributing to socioeconomic advancement negotiated. This requires opening up the innovation process to both obvious and non-obvious individuals, i.e. those within and outside existing innovation systems, and targeting in particular: 1) women scientists and engineers already formally participating in research and innovation, or involved in knowledge production, application and communication; 2) highly trained women located outside the formal systems who can contribute informed ideas to knowledge-related activities, including formulating market needs; and 3) other 'layperson' groups of women in their roles as socioeconomic agents (tax payers, opinion makers, consumers, decision makers). Through the use of participatory methods, it is possible, we believe, to effectively harness the, so far, underutilised innovation capability of these groups with considerable effectiveness, and to gather and explore the technical and economic viability of wide range of possible innovation ideas and solutions, linked to the available knowledge of when, why and how sex/gender differences can determine efficacy of outcomes.

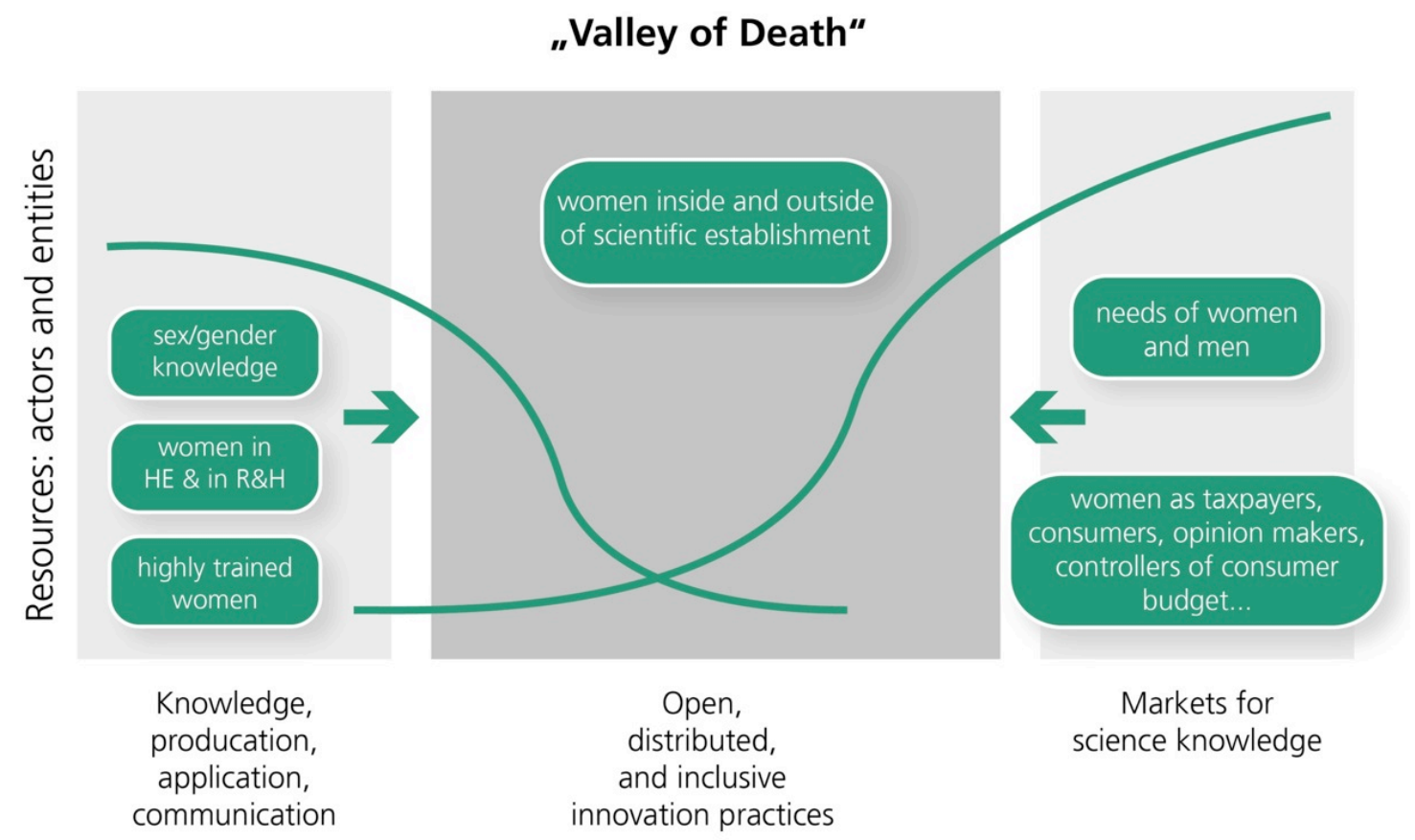

Figure 1. An innovation ecosystem from a gender perspective 
This leads to four scenarios of possible gender dynamics and their influence within an innovation ecosystem:

- Discovery led innovation process where the driver is new research showing important differences in the biological characteristics of women and men. An example is the discovery that the metabolic profiles of women and men are significantly different, and, therefore, women and men may need separate diagnostic biomarkers for metabolic diseases to ensure correct diagnostic efficacy for each [16].

- Quality led innovation process where a product already exists and is in use but a safer solution would be an advantage. A good example is breast cancer screening equipment, which traditionally uses ionizing radiation, the exposure to which is known to be more harmful to women than to men [17]. An alternative approach is to use radio wave technology, which would reduce risk of post-radiation cancer linked to the damage caused by accumulated exposures to ionizing radiation.

- Efficacy led innovation process where a product exists but the accuracy of its performance can be improved by making it sensitive to known sex-gender differences. An example is applying existing knowledge of sex differences in the symptoms and treatment of heart failure to improve performance of stenting devices for women and men [18].

- Impact led innovation process where the research knowledge used to develop new technologies may be independent of sex or gender considerations, but these technologies can have important socioeconomic impacts by improving the lives of women, for example. The nano and 'lab-on-the-chip' technologies when used to develop environmental sensors for remote testing of water safety are such an example. The gender aspect comes into play because access to safe water in developing countries could greatly improve the health of women living there.

We explain the underlying gender connections in more details in the sections that follow.

\subsection{Gender as Component of Innovation System Success}

The best and perhaps the most important example showing the use of gender as component of innovation success is provided by the European Union's latest Framework Programme for Research and Innovation for 2014-2020 period, Horizon 2020 (http://ec.europa.eu/programmes/hori zon2020/). The gender element of the success is to be measured in terms of increased participation of women in scientific and technical roles; integration of gender dimension in research and innovation content; and advancement of cross cutting impacts of gender mainstreaming across a wide variety of Horizon 2020 research topics [19]. Horizon 2020 includes research and innovation targeting grand societal challenges, such as climate change, transport, energy, cities of the future, and it is possible to envisage that each challenge could provide an opportunity to construct gender-sensitive innovation ecosystem.

\subsection{Gender as Component of Knowledge Activities}

Improving effectiveness of innovation by incorporating gender as component of knowledge development and knowledge exchange activities can be achieved in three ways: through new discoveries; through new application of existing sex/gender knowledge; and through enhancement of cognitive capacity underlying these activities.

In the first case, the focus is on producing new scientific discoveries through research using gender and/or sex as primary variables and results that show important sex-gender differences, which can (or should) be used as a source for new innovation ideas. For example, the discovery that the metabolic profiles of women and men are significantly different means that, potentially, there is a need for two markets for diagnostic biomarkers for diseases linked to metabolic disorders such as diabetes and Alzheimer's [16] one for women and the other for men.

In the second case, the focus is on applying already available understanding of when, why and how sex-gender differences matter to improve the design and performance of existing products so that they produce equally good outcomes for women and men. An example is provided by safety equipment used in cars to protect driver and passengers. Women drivers have been shown to have 47 per cent higher risk of serious injury in vehicle collision than men [20]. This has been explained in terms of important differences in the anatomy and morphology of women's bodies compared to the bodies of men, which play critical role in how the body and the organs within respond to the biomechanical forces produced during car crash. Historically, safety of cars has been tested using male crash test dummies (partly because, historically, men used to drive and women did not), so far, there are no female crash test dummies, but research does show that car safety equipment (car seat, head support, seat belt) often does not offer the same degree of protection to women as it does to men [21].

The third contribution gender can make to help improve effectiveness of innovation activities is by influencing team performance. Studies show, for instance, that improving gender balance among members of a group increases collective intelligence of the group [22]. One of the observed differences shows that women and men tend to communicate and share knowledge differently with women displaying greater sensitivity to communication cues, which enables wider variety of points of view to emerge and be jointly scrutinised. Other positive gender-related cognitive effects include better problem solving through the inclusion of different reasoning styles; better leadership through different management styles [23]; and more level attitudes to risk [24], which together can promote solutions that are well informed, have been analysed from many different perspectives, and 
are neither too cautious nor too reckless in their assumptions and goals.

An added but important benefit of actions to improve women's participation in innovation is the impact that this will have on gender stereotypes, for instance, the view that "women are hostile to innovation" [25], and also the benefits that will be obtained from increasing the availability of diverse role models. Although, historically, female scientists have been shown to engage in innovation and commercialisation of knowledge, overall they have done this at much lower levels than their male counterparts, and have been less likely to be granted a patent than men [26]. These differences are not fixed, however, the underlying innovation and organisational cultures, and how innovation activities are organised, do matter to how women and men respond to innovation opportunities. For example, when the patenting results for over 1,000 life scientists were examined, the results showed that male scientists in industry patented more than females, but that, generally, the disparity was substantially less in academia [27].

\subsection{Gender as Component of Improved Capacity of Human Capital Resources}

Increasing female representation in engineering fields and preventing them from leaving once they have entered these fields is of key importance to the development of human capital resources for innovation. Hunt 2012 [27] shows that women trained as engineers disproportionately leave engineering jobs due to dissatisfaction with pay and promotion. Within an open and inclusive innovation ecosystem the women who do leave could still be engaged in innovation activities, and participate in knowledge exchanges, entrepreneurial activities, formation of markets, and mobilisation of resources.

Participation in tertiary education is often used as a proxy indicator for measuring the capacity of innovation human capital resources [28]. In Europe, but also elsewhere, more women than men participate in higher education but with the exception of life science, they are underrepresented across most STEM fields linked to technological innovation, such as physics, chemistry, and engineering, and this happens at all levels [29, 30]. Without more female role models, 'male' attitudes to innovation will continue to be reinforced [31].

Firms and governments interested in deploying the full innovation capacity of their human capital resources would be advised to consider barriers preventing greater participation of women in innovation. The diversity of women's career pathways [32] should be seen as a positive factor. Rather than rewarding careers that follow the traditional model of advancement, which expects early success followed by steady linear progress in a narrow field [33], diversity of career experiences fits in very well with the variety of activities taking place in an innovation system.
In the case of life science, more women gain PhDs than men [13], and so the question has to be why they are missing in health innovation systems? As an indicator of the underutilization of women's innovation potential is the fact that only $8 \%$ of the patent applications submitted to the European Patents Office come from women [34]. Murray 2007 [35] shows that although the capacity of junior female scientists to commercialise their knowledge is not as strong at the beginning of their careers as of their male colleagues, mentoring and the presence of role models, and institutional support can change this. Women are able to patent as well as men $[36,37]$ and can be as eager as men to embrace entrepreneurship [38].

By promoting female role models [39] we can motivate larger numbers of young women to pursue careers relevant to innovation. Our own research on role models draws from Gibson's approach [40], which we use to define role models not as single example individuals but as cognitive constructs that can be "synthesised" from numerous examples of successful careers. In fields where men significantly outnumber women, and where male-gendered structures and leadership styles prevail, constructs that are based on a collection of exemplary women's careers can provide an effective transformational tool to support career development decisions.

The Fraunhofer team conducted a survey of the career preference profiles of 400 members of the alumni association called UNITECH [41] to see how they are influenced in their career preferences by company cultures, and what do they expect from their jobs and careers. In the face of fierce competition, on-going demographic changes, and the increasing skills shortage, many organizations are intensifying employer branding and head hunting. To their both actual and potential employees, most companies promote their cultures as flexible, family-friendly, and prioritizing work-life balance, and claim to provide clarity of working processes, great work autonomy, and ample opportunities for career advancement. The UNITECH survey is part of an on-going work at Fraunhofer to test if the perceptions of the employees' match their company's visions as an employer.

The UNITECH study revealed seven distinctive traits of the female subjects surveyed, see Figure 2 below, which have strong relevance to the aspirations of firms and governments to strengthen organisational or national innovation capacity. The key traits are mobility, flexibility, entrepreneurship and ambition. The results of the survey show that both women and men want to work in an environment that is flexible, and they want careers that allow them to be mobile. Women want professional development, and have high career aspirations, and a strong entrepreneurial spirit. However, women want more job security than men. 


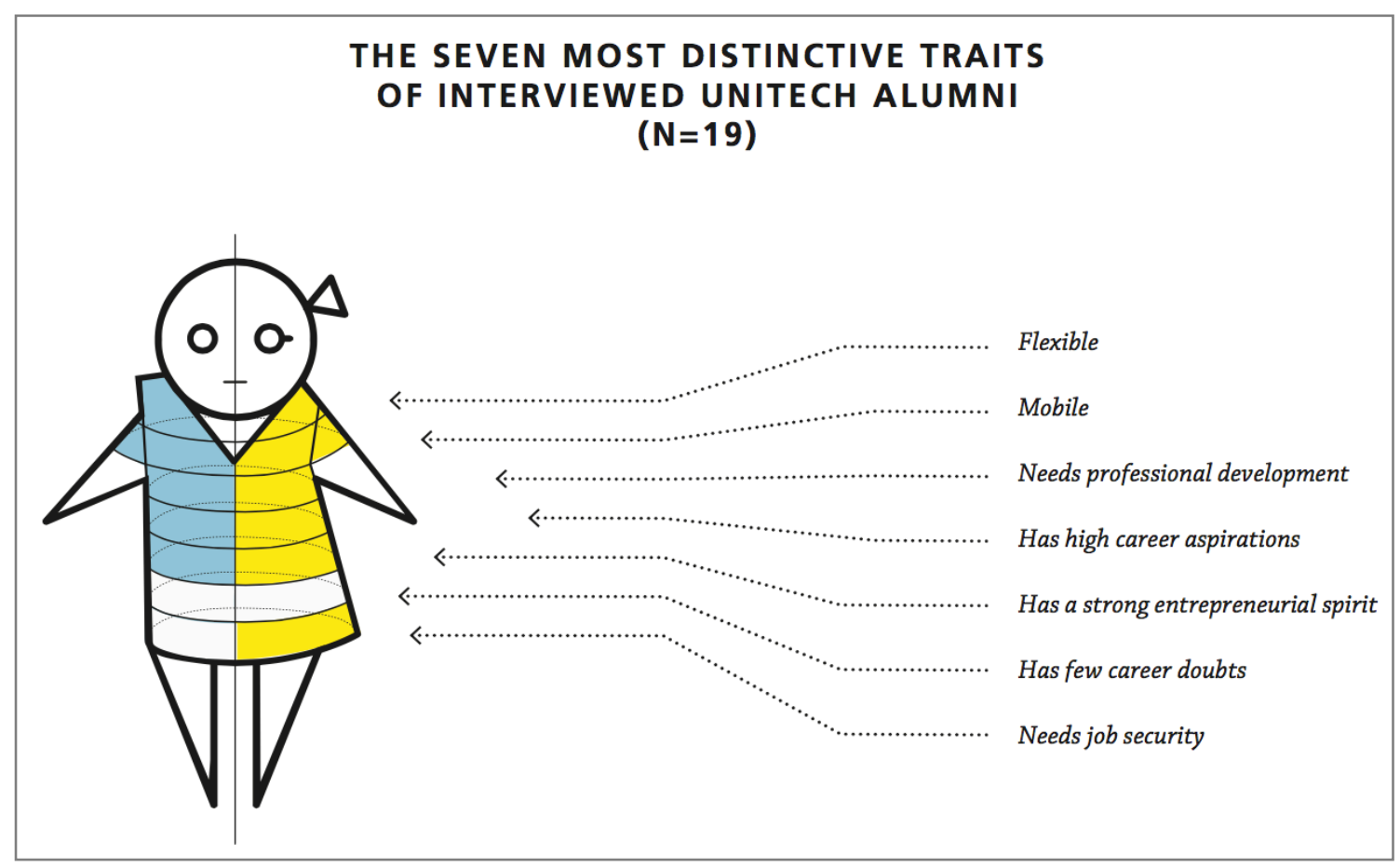

Figure 2. Key human capital characteristics of female STEM talent; adapted from [44]

We also conducted quantitative analysis of $1135 \mathrm{CVs}$ of the women listed on the AcademiaNet website - an online database of successful female scientists, most of them European [42]. This analysis was motivated by the desire to help women access and construct effective role models by identifying important attributes of a successful career pathway, such as career development pace and trajectory, and the degree of integration into the scientific community. It also compared career patterns in in male- versus femaledominated fields.

Importantly, the examined CVs show great diversity in the career pathways of women scientists and engineers. They also show that careers of younger scientists were developing significantly faster $(p<.001)$ than those of their older colleagues. One particular feature of this diversity is cross-sector mobility, a feature that suggests widening of the scope of professional experience, which should make them well suited to the effectiveness of innovation systems. Studies of innovation systems often quote movement of highly skilled people, whether they are students or experienced professionals, as their key success factor [28]. Our study shows that the CVs of women in male-dominated fields display significantly lower institutional and international mobility $(\mathrm{p}<.01)$ and higher sector mobility $(p<.001)$. Results concerning sector rotations are particularly visible in relation to time spent in industry, which was significantly higher in male-dominated than in female-dominated research fields. With regard to "city rotation' and taking into account differences in age, the younger women in the sample were as mobile as the older ones.

\subsection{Market Opportunities and Resistance to Change}

The gender sensitive innovation ecosystem shown in Figure 1 identifies several contexts at the market side where gender can play an influencing role. There are three economic arguments to support this: 1) women's influence as consumers has been growing - a phenomenon economists call 'womenomics' [43]; 2) their socioeconomic role is also improving-e.g. as tax payers and opinion influencers; and 3) the needs and expectations women and men have regarding what innovation can do for them can differ significantly, which may become a source of resistance to technological change.

Silverstein 2009 [44] estimated that globally, women control around \$20 trillion in annual consumer spending, which they predicted at the time would grow to $\$ 28$ trillion by 2015 . They also calculated that women's $\$ 13$ trillion in total yearly earnings in 2009 would reach $\$ 18$ trillion in 2015 . In aggregate, this means that women represent a growth market bigger than China and India combined - more than twice as big, in fact.

McKinsey 2015 [45] calculated that when a "full-potential" scenario is applied in which women participate in the economy identically to men, this would add up to $\$ 28$ trillion, or 26 per cent to annual global GDP in 2025, compared with a business-as-usual scenario. This impact, McKinsey report says is roughly equivalent to the size of the combined US and Chinese economies. 


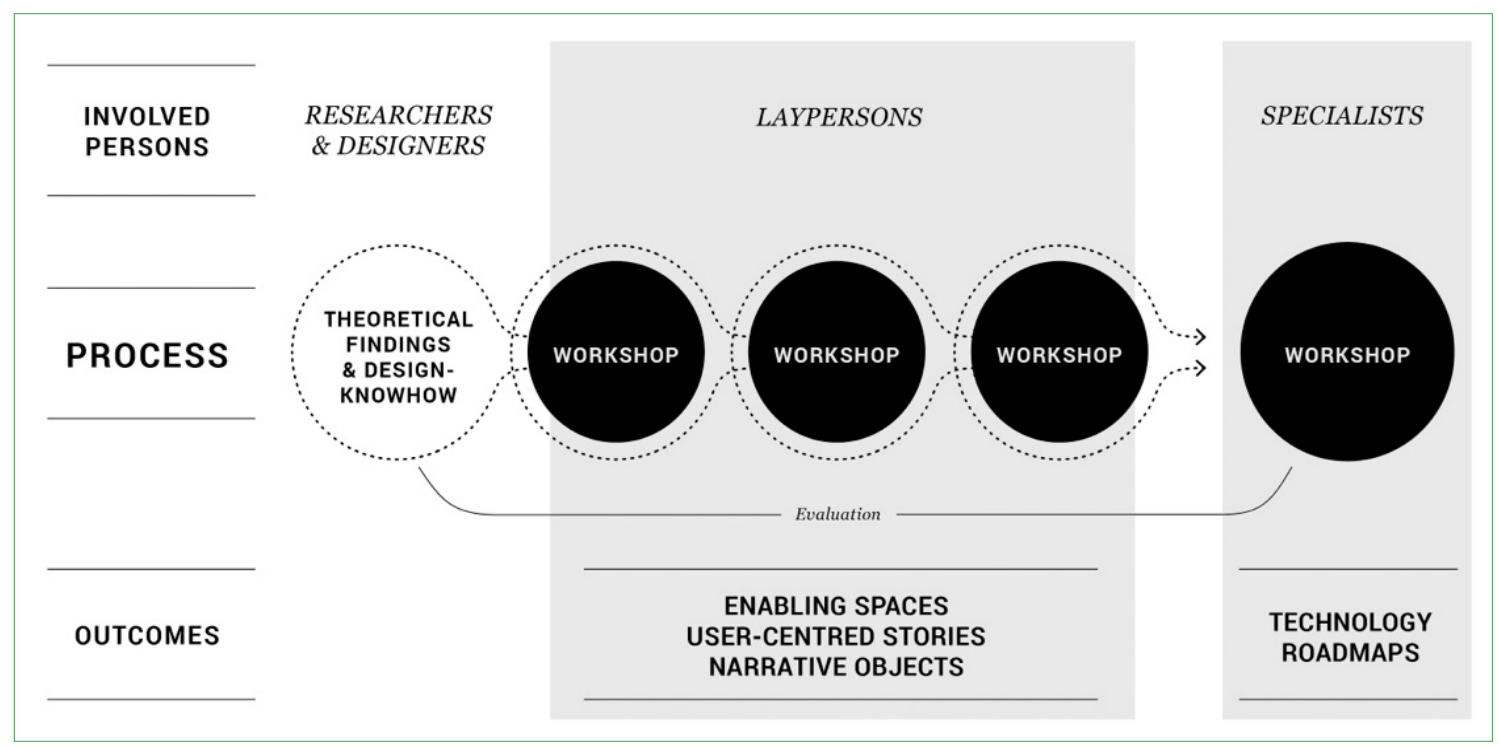

Figure 3. Discover Market participatory method, which involves layperson in identifying market need. They are involved in idea creation, which are then checked by engineers to validate that they can be implemented

Historically, the innovation needs of women, and their role in market activities, have been neglected, perhaps, because they were invisible as actors in the innovation systems. Such omissions can encourage resistance to change; when, in 2005, Eurobarometer study [25] interviewed 25,000 citizens in the $25 \mathrm{EU}$ member states to measure public attitudes towards innovation, they identified signs of weariness among women in particular. The study reported that $50 \%$ of those interviewed were either "anti-innovation" or "reluctant" to embrace innovative products or services and these two groups consisted mainly of women over 40 years of age, but also generally of people with lower level of education, living alone, and economically inactive. The other $50 \%$ of those interviewed were categorised as "attracted" to innovation or "enthusiasts" and they were composed of mainly young men, managers, and students. These conclusions risk promoting gender-stereotyped attitudes to technology products biased towards the interests and aspirations of men, but they also raise the question why would women be more reticent in their attitudes to innovation than men? Elsewhere, researchers found that when analysing products and user experiences from a gender perspective it was essential to distinguish between the different ways in which women and men value innovation. For women, the key determinants are: the value dimension; the functions/benefit dimension; the interaction dimension; the aesthetic dimension; the communication dimension. Each of these dimensions can be subject to gender bias, and therefore when considering women's needs it is important to focus on creating the whole user experience [46].

In the case of the Discover Markets method, described in Figure 3 above, acceptance of the need and benefits of innovation is achieved by synchronising two important conditions of success: that the product answers a concrete need and that it works well for the target users/consumers.
The Discover Markets approach achieves this goal by using a participatory method involving 'laypersons' (i.e. not engineers or technicians) in the market-related innovation idea creation process. Once the solution ideas have been identified, they are passed to Fraunhofer engineers for validity check, who decide if each of the proposed ideas can be implemented.

Our second example, is the website used by industry, called www.innocentive.com. Laboratories of large R\&D intensive companies can broadcast there problems their engineers cannot solve. The Innocentive community is made up of self-selected problem solvers, who submit solutions to the posted problems: there is a financial reward for the winning solution. When the technical and social profiles of the winners involved in 166 science problem solving contests with over 12,000 scientists participating as problem solvers - were analysed, the results revealed that the prospect of submitting a winning solution was positively related to increasing distance between the solver's field of technical expertise and the focal field of the problem [47]. Furthermore, female solvers - known to be in the "outer circle" of the scientific establishment - performed significantly better than men in developing successful solutions. These findings confirm the benefits of open and distributed innovation in the sense of disclosing problems and removing barriers to entry to non-obvious individuals. This example also shows the effectiveness of a market-mechanism to draw out knowledge from diverse external sources to solve internal problems [48]

\section{Conclusions}

We have identified three most important success-influencing roles that gender can play in innovation ecosystems, namely as: 
- component of knowledge activities - where it helps ensure quality, relevance and applicability of innovation by removing the risk of gender bias embedded in the knowledge influencing the innovations based on this knowledge

- component of innovation capacity of human capital resources - where it helps expand and diversify the profile and quality of available talent by including more women, and from different sectors and in different roles, in knowledge, entrepreneurial, and market-related activities

- component of markets - where it defines the different needs and preferences of women and men for innovation, and influences acceptance or resistance to technological change.

We have shown that 'gender blind' innovation systems carry the risk of using gender biased, and therefore flawed knowledge, which can result in gender-biased, flawed innovations and products with different quality of effectiveness for women and men. We have also stressed that inclusion of the knowledge of how and why sex-gender differences occur can open up new opportunities to develop fresh markets for science knowledge, and the areas of particular current opportunity include human safety, health, and security.

Increasingly, countries compete on the basis of their innovation capacity and effectiveness, which is seen by policy makers as a fundamental source of wealth generation within an economy, and a way to stimulate job creation. Ignoring the different roles that gender can play in innovation systems is a strategic flaw that can hamper the capacity of innovation systems to recognise and take advantage of new opportunities to improve the effectiveness of research and innovation outcomes for women and men, and achieve socioeconomic progress for all through innovation.

\section{REFERENCES}

[1] J.Tidd, A review of innovation models, Discussion Paper 1, Imperial College London 2006. Available online from: http://www.emotools.com/static/upload/files/innovation_mo dels.pdf

[2] G. D. Markman, D. S. Siegel and M, Wright, Research and Technology Commercialization, Journal of Management Studies, Volume 45, Issue 8, pages 1401-1423, December 2008

[3] L. Leydesdorff, The Triple Helix of

University-Industry-Government Relations (February 2012)

Encyclopedia of Creativity, Innovation, and Entrepreneurship, Springer, New York.

[4] U.S. Department for Commerce, Economics and Statistics Administration, Women in STEM: A Gender Gap to Innovation, ESA Issue Brief 04-11, 2011. Online available from www.esa.doc.gov
[5] M. Hekkert, S. Negro, G. Heimeriks, and R. Harmsen, Technological innovation Systems Analysis, Faculty of Geosciences, Copernicus Institute for Sustainable Development and Innovation, November 2011

[6] D. Gibon, Ed. Natural Language Processing and Speech Technology. Results from the $3^{\text {rd }}$ KONVENS Conference, Bielefeld, October 1996, Mouton de Gruyter Berlin-New York 1996.

[7] N. Slocum, Participatory Methods Toolkit A practitioner's manual, King Baudouin Foundation and the Flemish Institute for Science and Technology Assessment, December 2003, On line available from

http://archive.unu.edu/hq/library/Collection/PDF_files/CRIS /PMT.pdf

[8] Recommendations for Action on the Gender Dimension in Science, genSET Consensus Report 2010. Online available from:

http://www.genderinscience.org/index.php/consensus-semin ars/recommendations-report

[9] S. Buitendijk, D. Corda, A. Flodström, Anita Holdcroft, Jackie Hunter, Elizabeth Pollitzer, Teresa Rees, Curt Rice, Londa Schiebinger, Martina Schraudner, Karen Sjørup, Rolf Tarrach, Women in science and medicine, The Lancet, 2011, 377, p811. Online available from:

http://www.thelancet.com/pdfs/journals/lancet/PIIS0140-673 6(11)60305-X.pdf

[10] A. K. Beery and I. Zucker, Sex Bias in Neuroscience and Biomedical Research, Neurosci Biobehav Rev. 2011 Jan; 35(3): 565-572.

[11] E. Pollitzer, Cell Sex Matters, Nature, 1 August 2013, Vol 500: 23-24.

[12] J. Nählinder , M. Tillmar , C. Wigren , Towards a gender-aware understanding of innovation: a three-dimensional route", International Journal of Gender and Entrepreneurship, 2015, Vol. 7 Issue: 1, pp.66-86

[13] European Commission, She Figures 2012. Gender in research and innovation, 2013. Online available from: http://ec.europa.eu/research/science-society/document_librar y/pdf_06/she-figures-2012_en.pdf

[14] M. Schraudner, Discover Markets, 2013. Online available from: http://www.cerri.fraunhofer.de/

[15] D. J. Jackson, What is an innovation ecosystem?, 2011. Online available from: http:/erc-assoc.org/sites/default/files/topics/ policy_studies/DJackson_Innovation\%20Ecosystem_03-1511.pdf

[16] K. Mittelstrass, J. S. Ried, Z. Yu, J. Krumsiek, C. Gieger, C. Prehn,W. Roemisch-Margl, A. Polonikov, A. Peters, F. J. Theis, T. Meitinger, F. Kronenberg, S. Weidinger, H. E. Wichmann, K. Suhre, R. Wang-Sattler, J. Adamski , T. Illig, Discovery of Sexual Dimorphisms in Metabolic and Genetic Biomarkers. PLoS Genet 7(8), 2011.

[17] O.G. Raabe, Toward Improved Ionizing Radiation Safety Standards. Health Phys. 2011 Jul:101(1)84-93.

[18] J. Mehill, A. Kastrati, H. Bollwein, A. Dibra, H. Schuehlen, J. Dirschinger, A. Schoemig, Gender and Restenosis After Coronary Artery Stenting. European Heart Journal 2003, 24(16):1523-1530. 
[19] Vademecum on Gender Equality in Horizon 2020, February 2014. Online available from: https://ec.europa.eu/research/swafs/pdf/pub gender_equality /vademecum_gender_h2020.pdf

[20] D. Bose, M. Segui-Gomez, and J.R. Crandall, J.R., Vulnerability of female drivers involved in motor vehicle crashes: and analysis of US population at risk, Am J Public Health, 101(12), pp2368-2373, 2011.

[21] A. Linder, M. Svenson, A. Carlsson, P. Lemmen, F. Chang, K. Schmidtt, A. Kullgren, EvaRID - Anthropometric and biomechanical specification of a finite element dummy model of an average female for rear impact testing, Paper Number 11-0374, Swedish National Road and Transport Research Institute, 2011. Online available from: http://www.adseat.eu/files/pages/22/linder-et-al-esv-submitte d-2011-03-15-2-.pdf

[22] A. Williams Woolley, C.F. Chabris, A. Pentland, N. Hashmi, T.W. Malone, Evidence for a Collective Intelligence Factor in the Performance of Human Groups. Science Express Report, www.scienceexpress.org, 30 September 2010: 1-5.

[23] A. H. Eagly and B. T. Johnson, Gender and Leadership Style: A Meta-Analysis, CHIP Documents. Paper 11, 1990. Online available from:

http://digitalcommons.uconn.edu/chip_docs/11

[24] J.P.Byrnes, D.C. Miller, W.D. Schafer, Gender differences in risk taking: A meta-analysis, Psychological Bulletin, Vol 125(3), May 1999, 367-383, 1999.

[25] European Commission, Special Eurobarometer, Population Innovation Readiness, August 2005. Online available from: http://ec.europa.eu/public_opinion/archives/ebs/ebs_236_en. pdf

[26] Kordula Kugele, Chapter 7 Analysis of women's participation in high-technology patenting, in Pooran Wynarczyk, Susan Marlow (ed.) Innovating Women: Contributions to Technological Advancement (Contemporary Issues in Entrepreneurship Research, Volume 1), Emerald Group, 123 151 (2010).

[27] J. Hunt, J-P. Garant, H. Herman, D.J. Munoroe, Why don't women patent? IZA DP No. 6886, Discussion Paper Series, Institute for the Study of Labor, 2012.

[28] M. Schaaper, The Human Factor in Innovation, 2014. Online available from http://www.wipo.int/export/sites/www/econ_stat/en/economi cs/gii/pdf/2014/gii_2014_chapter_2.pdf

[29] G. Sonnert, M. Frank Fox and K. Adkins, Undergraduate Women in Science and Engineering: Effects of Faculty, Fields, and Institutions Over Time, Social Science Quarterly Volume 88, Issue 5, pages 1333-1356, December 2007

[30] S. J. Ceci, D.K Ginther, S. Kahn, W.M. Williams, Women in Academic Science: A Changing Landscape, Psychological Science in the Public Interest 2014, Vol. 15(3) 75-141.

[31] R. Graham, Creating university-based entrepreneurial ecosystems evidence from emerging world leaders, 2014. Online available from:

http://www.rhgraham.org/RHG/Recent_publications_files/M IT\%3ASkoltech $\% 20$ entrepreneurial $\% 20$ ecosystems $\% 20$ repo rt\%202014\%20_1.pdf
[32] C. Vinkengurg, C. Herschberg, S. Connolly and S. Fuchs, ERCAREER ERC-Support-2012-1 (317442) Fina Report short version (June 2014) Capturing career paths of ERC grantees and applicants: promoting sustainable excellence in science careers. Online available from: https://erc.europa.eu/sites/default/files/document/file/ERCA REER_final_report.pdf

[33] League of European Research Universities (LERU), Academic career maps in Europe, 2009. Online available from:

http://www.leru.org/index.php/public/extra/careermapseurop e/

[34] R. Frietsch, I. Haller, M.Vrohlings, H. Grupp, Gender-specific patterns in patenting and publishing, Fraunhofer ISI Discussion Papers Innovation Systems and Policy Analysis, No. 16, 2008.

[35] F. Murray and L. Graham, Buying science and selling science: gender differences in the market for commercial science, Industrial and Corporate Change, 16(4), pp. 657-689, 2007

[36] W. W. Ding, F. Murray, and T. E. Stuart, Gender Differences in Patenting in the Academic Life Sciences, 313 Science, 665-667(2006).

[37] G.S. McMillan, Gender differences in patenting activity: An examination of the US biotechnology industry, 80 Scientometrics 685-693 (2009). Online available from: http://genet.csic.es/sites/default/files/documentos/biblioteca/ STEVEN\%20MCMILLAN_Gender\%20differences\%20in\% 20patenting\%20activity.pdf

[38] K. Bunker Whittington, Women Inventors in Context. Disparities in Patenting across Academia and Industry, Gender \& Society, vol. 22 No. 2, 194-218, April 2008

[39] Accepted for publication in Journal of Academic Perspectives: A. Trübswetter, A. Sinell, K. Best, M. Schraudner, Uncovering career patterns - how exemplary career paths can guide young female scientists. 2015

[40] D.E. Gibson, Role Models in Career Development: New Directions for Theory and Research." Journal of Vocational Behavior 65:134-156, 2004.

[41] To appear in International Journal of Gender, Science and Technology in 2015: A. Trübswetter, K. Genz, K. Hochfeld, M. Schraudner, Corporate Culture matters - what kinds of workplaces appeal to highly skilled engineers?

[42] Robert Bosch Foundation, The Portal to Excellent Women Academics, Academia Net, www.academia-net.org

[43] Womenomics revisited, Economist, 19 April 2007. Online available from: http://www.economist.com/node/9038760

[44] M. J. Silverstein and K. Sayre, The Female Economy, Harvard Business Review, September 2009. Online available from: https://hbr.org/2009/09/the-female-economy

[45] McKinsey Global Institute, The power of parity: How advancing women's equality can add $\$ 12$ trillion to global growth. September 2015

[46] K. Schroeder, Gender Dimensions of Product Design, UN Women Expert group meeting Gender, science and technology, Paris 28 September - 1 October, 2010

[47] L.B. Jeppesen and K.R. Lakhani, Marginality and problem 
solving effectiveness in broadcast search, 2010. Online available from:

http://dash.harvard.edu/bitstream/handle/1/3351241/Jeppese $\mathrm{n}$ Marginality.pdf?sequence $=2$
[48] K. J. Boudreau and K. R. Lakhani, Using the crowd as your innovation partner, Harvard Business Review, April 2013. Online available at

https://hbr.org/2013/04/using-the-crowd-as-an-innovation-pa rtner/ 